\title{
COMMUNICATIONS
}

\section{GLAUCOMA AND INACTIVE SYPHILITIC INTERSTITIAL KERATITIS*}

\author{
BY \\ M. J. A. BRITTEN AND C. A. L. PALMER $\dagger$ \\ From the Department of Ophthalmology, University of Manchester
}

THE concept of an association between congenital syphilitic interstitial keratitis and the development of late glaucoma is not new. Hutchinson (1863) reported the case of a man aged 24 with congenital syphilis who had suffered bilateral interstitial keratitis at the age of 6; both eyes had deeply cupped and atrophic optic discs and iridectomy failed to control the glaucoma. Hutchinson believed that the glaucoma was due to the interstitial keratitis. Fuchs (1899) said that "an increase of tension is but rarely observed, and, when it is, sometimes occurs years after the inflammation has run its course". de Schweinitz (1916) stated that "secondary glaucoma may develop, with deep cupping of the disc", but gave no interval.

Kraupa (1934) reported three cases of late glaucoma following interstitial keratitis. Schulmann (1934) described glaucoma 4 years after bilateral interstitial keratitis. Duke-Elder (1938a) recognized that secondary glaucoma might follow the uveitis of interstitial keratitis.

Knox (1961) recorded fourteen instances of delayed glaucoma occurring in 88 patients with inactive interstitial keratitis found in the diagnostic files of the Johns Hopkins Hospital for the years 1936 to 1952. In addition, he described nine other cases of delayed glaucoma undergoing treatment. From this total of 23 patients, he recognized two dissimilar modes of onset: in fifteen patients the onset was insidious and resembled that of chronic simple glaucoma, and in eight it was relatively acute. The age at onset of glaucoma varied between 23 and 70 years, the peak occurring between 33 and 35 years. There was a marked variation in the interval between active keratitis and the onset of glaucoma.

In six of Knox's patients gonioscopy was done and showed similar findings. There were open angles with small finger-like peripheral anterior synechiae; the trabecular area was noted to be a dense grey to white in colour, Schwalbe's line being poorly defined. Knox suggested that there was an increased density or hyalinization of the trabecular area.

He made two suggestions as to pathogenesis:

(i) That interstitial keratitis hastened an ageing or degenerative process, producing an open-angle type of glaucoma;

(ii) That a low-grade, subclinical recurrence of the keratitis involved the trabeculae in the inflammatory process and produced a rapid rise in the resistance to aqueous outflow.

He suggested that these two mechanisms might explain the insidious and acute modes of onset respectively.

* Received for publication August 6, 1963

+ Present address: The Royal Infirmary, Sheffield.

13 
Sugar (1962) reported four cases of late glaucoma following interstitial keratitis. He emphasized that all his patients had shallow anterior chambers and a course resembling subacute or chronic angle-closure glaucoma. In two eyes peripheral iridectomy was effective, and in one the histological findings indicated an angleclosure mechanism. The horizontal corneal diameters were between 10.5 and 11.5 $\mathrm{mm}$. and Sugar postulated that microcornea due to congenital syphilitic interstitial keratitis might result in angle-closure glaucoma. On the other hand, he believed that another type of late glaucoma following interstitial keratitis existed, namely, a variety of trabecular space obstruction and pathological alterations involving the presence of connective tissue attributable to the uveitis.

The present communication reports a study approaching the problem from two directions:

(1) A series of patients with congenital syphilis and inactive interstitial keratitis was examined, with particular reference to the state of the filtration angle.

(2) Seven patients with inactive interstitial keratitis and known glaucoma were reexamined, to establish the nature of the relationship, if any.

\section{A Survey of 95 Patients with Inactive Interstitial Keratitis}

\section{Material and Methods}

The records for the years 1935 to 1962 of the Department of Venereal Diseases at the Manchester Royal Infirmary and the Manchester Royal Eye Hospital were searched for cases of congenital syphilis with inactive interstitial keratitis. A circular was sent to the 520 patients found, of whom 109 were traced and examined.

In addition to taking a full history and making a routine examination, applanation tonometry, gonioscopy, and tonography were carried out where the state of the cornea and the age and the cooperation of the patient allowed. The gonioscopic findings were recorded employing the classification of Gorin and Posner (1957), and for tonography a Schwarzer Electrotonometer was used, the coefficient of outflow being calculated from the Friedenwald Nomogram. Perimetry was not carried out where poor fixation or deafness rendered the results unreliable or where the optic disc was pink and flat and the tension and tonography readings normal. It was, however, attempted where especially indicated together with the relevant provocative tests.

\section{Results}

Fourteen of the 109 patients could not be proved to have had interstitial keratitis and were therefore excluded from the series, while fourteen others had only one eye affected and two were uniocular; 95 patients and 174 eyes therefore remained in the series.

The ages of the patients in this series at the time of the first attack of interstitial keratitis (Fig. 1, opposite) resembled those in other series (Cunningham, 1922; Spicer, 1924). Fig. 2 (opposite) shows the present ages of the patients and Fig. 3 (opposite) the time which has elapsed since their first attack of interstitial keratitis.

Slit-lamp microscopy was performed on every case and an unexpected finding was the high incidence of patent vessels in the corneae, which, apart from the persistent circulation, did not differ from the classical obliterated "ghost" vessels. 


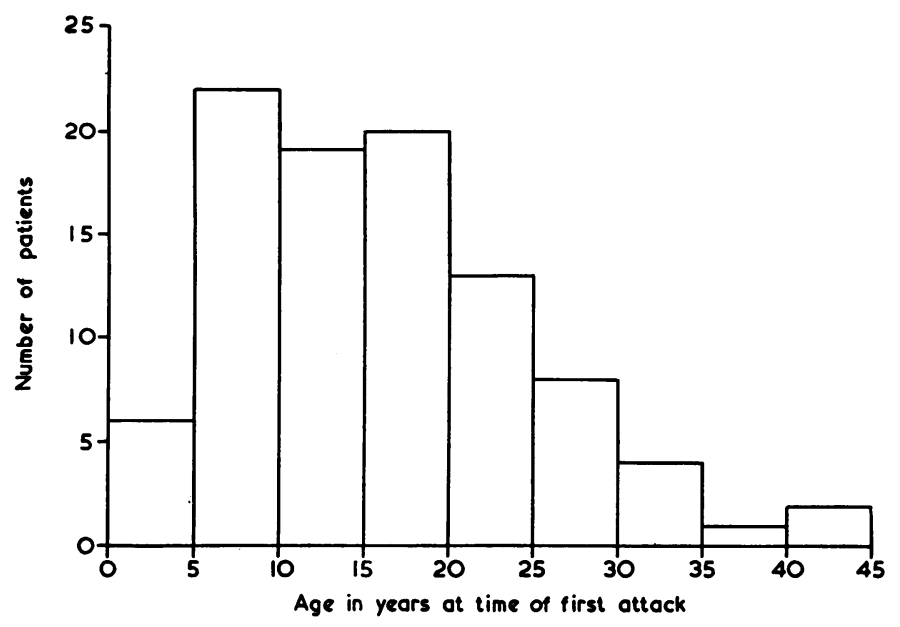

FIG. 1.-Age at onset of interstitial keratitis.

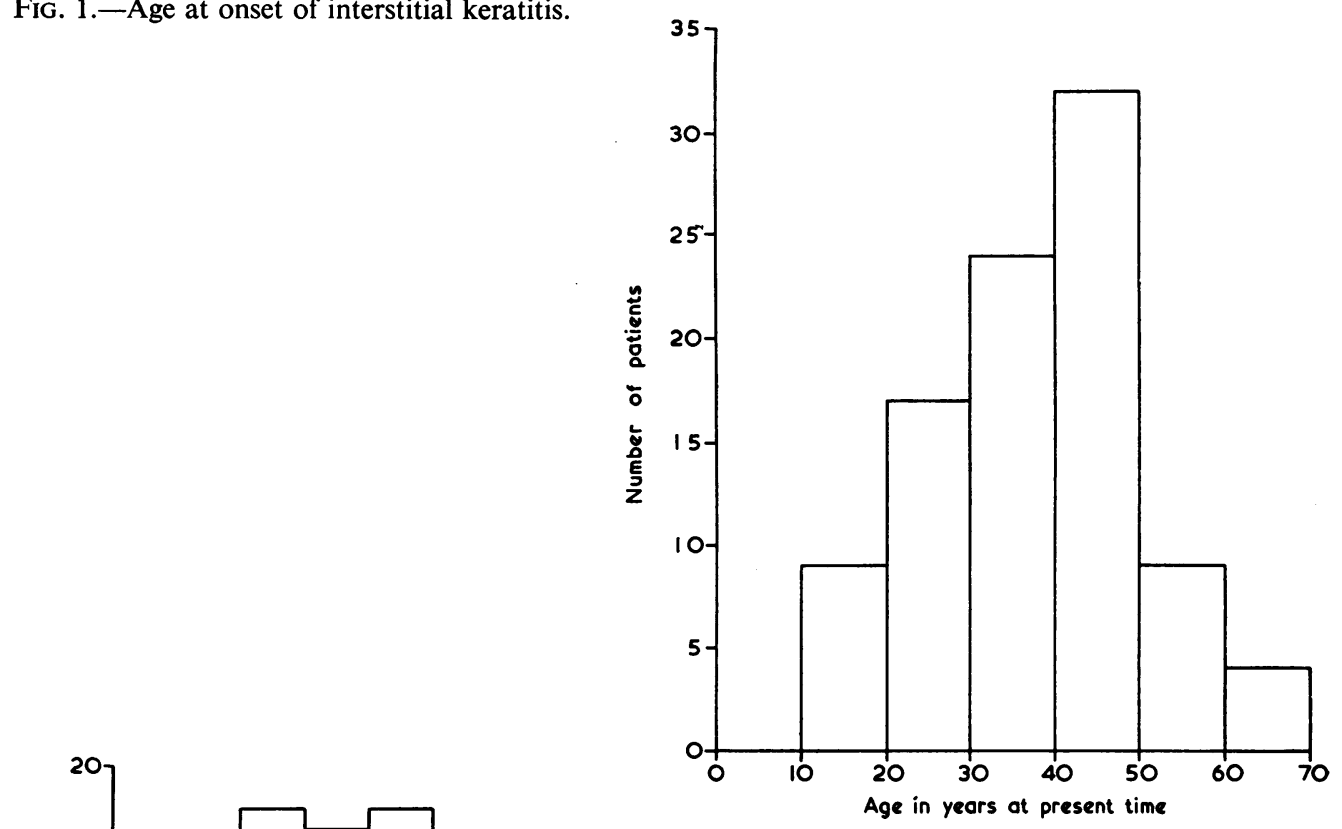

Fig. 2.-Present age.

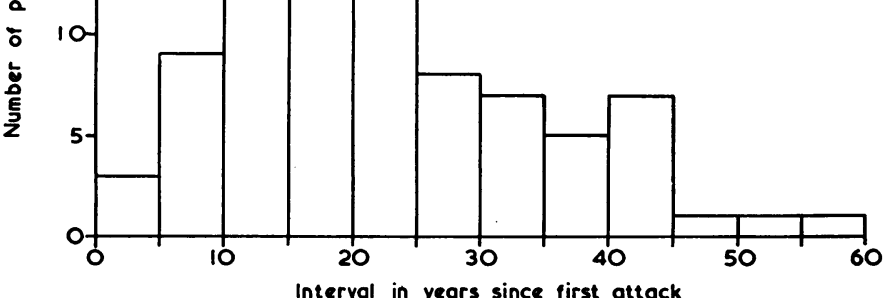

Fig. 3.-Interval between present age and onset of interstitial keratitis. 
Duke-Elder (1938b) stated that, although the vessels remained throughout life, they ceased to carry blood. Table I shows that many corneae contain both patent and ghost vessels, but that occasionally all the vessels remain patent. The densities of the corneal nebulae were graded according to a clinical assessment.

TABLE I

CORNEAL CHANGES IN 174 EYES WITH INACTIVE INTERSTITIAL KERATITIS

\begin{tabular}{l|c|c|c|c|c}
\hline \multirow{2}{*}{$\begin{array}{c}\text { Occurrence and State of Deep Corneal } \\
\text { Blood Vessels }\end{array}$} & \multicolumn{3}{|c}{ Occurrence and Density of Corneal Nebulae } \\
\cline { 2 - 6 } & None & Mild & Moderate & Severe & Total \\
\hline None & 22 & 15 & - & $1^{*}$ & 38 \\
Ghost and Patent & 3 & 55 & 16 & 3 & 77 \\
Ghost Only \\
Patent Only & 2 & 34 & 1 & - & 37 \\
\hline \multicolumn{1}{c|}{ Total } & 35 & 115 & 20 & 4 & 174 \\
\hline
\end{tabular}

* In this case a diffuse and severe nebula precluded any view of deeper stromal layers

Nineteen of the 22 eyes showing neither nebulae nor corneal blood vessels had been treated in the active stage with topical cortisone; this agrees with the finding of Ashworth (1958) that many eyes escape with clear corneae following early treatment with cortisone.

Tonometry.-The tensions of 168 eyes were recorded by applanation tonometry; in the remaining six eyes tonometry proved impossible, either because of the youth of the patient or because of the presence of gross corneal irregularity. Two eyes with tensions above $30 \mathrm{~mm}$. $\mathrm{Hg}$ (Schiötz) were proved to have glaucoma (Table III, below, Cases 8 and 9) and the remaining 166 eyes all had tensions of $20 \mathrm{~mm}$. Hg or less, seventeen being in the abnormally low range of 5 to $9 \mathrm{~mm}$. $\mathrm{Hg}$.

Tonography. -121 eyes were submitted to tonography and of these only six had coefficients of outflow of less than $0 \cdot 20$. Of three with very low coefficients of outflow, two proved to have glaucoma (Cases 8 and 9); the third, which was nearly blind from a combination of long-standing retinal detachment and syphilitic optic atrophy, had an outflow coefficient of $0 \cdot 11$ but an applanation tension of only 10 $\mathrm{mm}$. $\mathrm{Hg}$; this was a soft degenerate eye which has been excluded from further consideration.

The remaining three eyes had coefficients of outflow of between $0 \cdot 17$ and $0 \cdot 19$, but showed no significant change in either tension or outflow following the ingestion of one litre of water. In one of them approximately 90 per cent. of the filtration angle was closed by anterior synechiae, whilst the other two had normal angles.

Gonioscopy (Table II, opposite).-An adequate view of the anterior chamber angle was obtained in 129 eyes, of which 81 were normal; in the remaining 48 the changes consisted mainly of typical post-inflammatory peripheral anterior synechiae, but in a small number other abnormalities were seen either alone or in addition to the synechiae. One such abnormality was seen in twelve eyes in which we described the angles as looking "structureless"; the peripheral parts of the posterior corneal surface had a dense white matt appearance which partially continued on to the trabeculae and into 
the depths of the angle, blurring the outline and rounding the contours of the structures. None showed any evidence of obstruction to outflow; indeed five had tensions of less than $10 \mathrm{~mm}$. $\mathrm{Hg}$.

TABLE II

GONIOSCOPIC FINDINGS IN 129 EYES WITH INACTIVE INTERSTITIAL KERATITIS

\begin{tabular}{l|c|c|c|c|c}
\hline $\begin{array}{c}\text { Percentage of } \\
\text { Peripheral Anterior } \\
\text { Synechiae }\end{array}$ & \multicolumn{4}{|c|}{ Abnormalities of the Angle Other than Anterior Synechiae } \\
\cline { 2 - 6 } & None & $\begin{array}{c}\text { Angles having a } \\
\text { "Structureless" } \\
\text { Appearance }\end{array}$ & $\begin{array}{c}\text { Angles with } \\
\text { Excessive } \\
\text { Pigmentation }\end{array}$ & $\begin{array}{c}\text { Angles Obscured } \\
\text { by a "Felt-like" } \\
\text { Membrane }\end{array}$ & Total \\
\hline \begin{tabular}{l|c|c|c|c} 
None \\
Less than 10
\end{tabular} & 81 & 5 & - & 1 & 1 \\
10 to 70 \\
More than 70 & 10 & 2 & 2 & 2 & 13 \\
\hline \multicolumn{1}{c|}{ Total } & 2 & - & 1 & 4 & 129 \\
\hline
\end{tabular}

Examples of two other abnormalities were seen:

Four eyes showed a brown felt-like membrane which extended from Schwalbe's line to the root of the iris, obscuring further details of the angle. All had normal tensions and normal coefficients of outflow.

Three eyes, all with brown irides, showed a heavy deposition of pigment which rendered the whole of the trabeculae, the scleral spur, and the depths of the angle a uniform brown colour; this colour blended well with the root of the iris and with the many peripheral anterior synechiae. In addition, one of them had 70 per cent. of the angle closed by anterior synechiae and had advanced glaucoma (Case 8), whilst the other two had 60 and 20 per cent. of their angles closed, but normal tensions and tonography readings.

Of the three eyes with 70 per cent. or more of their angles closed by synechiae, two have already been mentioned; the third (Case 9) had a deep anterior chamber, 100 per cent. peripheral anterior synechiae, and advanced glaucoma. No association was found between the width of the angle and the abnormalities described.

\section{Discussion}

The investigation described above was designed to examine the appearance and function of the filtration angle of eyes with inactive interstitial keratitis.

When discussing the findings, however, it is emphasized that some of the eyes were unsuitable for full investigation, and that those eyes which were fully examined may not necessarily be representative of the series as a whole. For instance, most of the eyes unsuitable for gonioscopic examination were either those with severe corneal nebulae or those of young patients; but, whilst the former were perhaps liable to have had a high incidence of angle changes, the latter, following local cortisone in the active stage of the disease, were more likely to have escaped without damage. There was also no way of assessing the severity of the original inflammation.

The two eyes with glaucoma both had deeply cupped and atrophic discs with raised tensions, low coefficients of outflow ( 0.00 and 0.03$)$, and extensive peripheral anterior 
synechiae which appeared to be post-inflammatory in origin. Their anterior chambers were too deep to suggest that the mechanism of the formation of their synechiae was that of classical "angle-closure". The details of these two patients are summarized in Table III (below, Cases 8 and 9).

Case 9 appeared to be one of delayed secondary glaucoma following 100 per cent. peripheral anterior synechiae, but Case 8 , in which 70 per cent. of the anterior chamber angle was occluded by synechiae, may have some added factor reducing outflow in the 30 per cent. which remained open. In this connexion Higgitt (1956) reported that, in cases of secondary glaucoma due to post-inflammatory peripheral anterior synechiae, at least 70 per cent. of the angle was blocked. The unusual pigmentation already described in Case 8 may have contributed to the reduction in outflow, but Tulloh (1960) considered that pigmentary deposition was not a contributory cause in secondary glaucoma, and further the other two eyes affected by similar pigmentation had normal tension and tonography readings, but only 60 and 20 per cent. of peripheral anterior synechiae.

Apart from the two eyes with glaucoma, none of the abnormal gonioscopic appearances found in this survey were associated with a reduction in outflow or a raised ocular tension.

Oksala (1957) reported trabecular synechiae in the active stage of interstitial keratitis and Knox (1961) described the gonioscopic appearances of six patients out of a series of 23 with inactive interstitial keratitis and glaucoma; each of the six had, in addition to open angles and small finger-like synechiae, a hyalinization or an increase in the density of the trabecular area, and from this description these changes would seem to be the same as those which we observed and described as "structureless". Assuming this to be so, these changes are unlikely per se to have been the cause of the glaucoma in his cases, since the twelve eyes with this appearance in our series all had normal coefficients of outflow and tensions of $20 \mathrm{~mm}$. Hg or less; they had an average interval of over 25 years since the onset of the interstitial keratitis. Similarly, the felt-like membrane seen in the anterior chamber angles of four eyes appeared to have no adverse affects upon filtration.

The seventeen eyes in the abnormally low range of 5 to $9 \mathrm{~mm}$. Hg showed no consistent angle changes, five appeared structureless, two had scattered anterior synechiae, and the remainder had no abnormality; it was difficult to estimate the coefficient of outflow in such soft eyes, but it was normal in the six submitted to tonography. The cause of the low tension may have been hyposecretion of aqueous following an unusually severe cyclitis in the active stage of the disease.

Only two patients with glaucoma were discovered among the 95 patients examined, but they were only 33 and 36 years of age and both had advanced glaucoma. There was otherwise a notable absence of eyes with tonometric or tonographic readings suggestive of glaucoma.

\section{Nine Cases of Inactive Interstitial Keratitis and Glaucoma}

In addition to the survey reported above, seven patients with inactive interstitial keratitis already known to be attending the Glaucoma Clinic in the University Department of Ophthalmology were re-examined to establish what connexion, if any, there might be between the two conditions. Table III (overleaf) summarizes 
their clinical features, and also those of the two cases of glaucoma revealed by the survey. All these patients have recently been re-examined to confirm the diagnosis of congenital syphilis.

Cases 1, 2, and 3 were difficult to classify clinically, and their angles were largely obscured by the corneal opacities. The clinical impression in Case 1 was that of chronic simple glaucoma although much of the angles was unseen.

During in-patient observation, Case 2 showed violent fluctuations of intra-ocular pressure in each eye, the peaks reaching $70 \mathrm{~mm}$. $\mathrm{Hg}$ and coinciding with the complaint of haloes and a reduction in the coefficient of outflow as shown by tonography. Anterior uveitis was never observed and, but for this, the hypertensive attacks resembled glaucomato-cyclitic crises. Homatropine and pilocarpine had no effect in the attacks, although partial control was obtained with Diamox.

Case 3 presented as "acute glaucoma" with shallow anterior chambers; the mechanism of this attack was probably angle-closure, although the anterior chambers were not so shallow as is usual in this condition, and the pupils (of the Argyll Robertson type) responded poorly to a mydriatic.

Cases 4, 5, and 6 presented the features of narrow-angle glaucoma in either the angle-closure or chronic closed-angle phases; they were typical in their symptoms and clinical findings, the only unusual feature being the evidence of old interstitial keratitis.

Cases 7, 8, and 9 were regarded as examples of true secondary glaucoma; each had extensive organic changes in the filtration angle of the affected eyes. The right eye of Case 7 had shown (before operation) a "gelatinous appearance at the root of the iris apparently occluding the angle" in the inferior segment, in addition to extensive peripheral anterior synechiae elsewhere. His left eye had a reduced coefficient of outflow after water-drinking and, although a rise in tension has yet to be recorded, careful follow-up is indicated.

\section{Comment}

Any consideration of this problem depends partly on an adequate view of the filtration angle; this was impossible in Cases 1, 2, and 3, and the mechanism of the ocular hypertension in these patients could not be determined with accuracy. It is felt, therefore, that conclusions cannot safely be drawn from them.

On the other hand, Cases 4, 5, and 6 appeared to be typical examples of narrowangle glaucoma and it is difficult to place the episodes of interstitial keratitis occurring 37 years earlier into a causal relationship with the glaucoma. They appear to resemble the four narrow-angle cases of Sugar (1962), but it seems unlikely that microcornea due to congenital syphilitic interstitial keratitis is implicated (as he suggested) since our three narrow-angle patients suffered the active keratitis at an age when the eye has already attained its full size and might be expected to have stopped growing. Only one patient (Case 6) had corneal diameters less than $11 \mathrm{~mm}$., below which value the description of microcornea is warranted (Duke-Elder, 1961).

It is not claimed, however, that a connexion between the interstitial keratitis and 
the late glaucoma in Cases 1 to 6 has been excluded with certainty; but it should be pointed out that there are difficulties in attributing glaucoma to interstitial keratitis, for two reasons. Firstly, precise gonioscopic examination is frequently impossible; secondly, where there is already an adequate explanation for the glaucoma in terms of a conventional and better understood mechanism (as in the three narrow-angle

TABLE

CLINICAL FEATURES OF NINE CASES OF

\begin{tabular}{|c|c|c|c|c|c|c|c|c|}
\hline $\begin{array}{l}\text { Case } \\
\text { No. }\end{array}$ & $\begin{array}{c}\text { Age } \\
\text { (yrs) }\end{array}$ & Sex & $\begin{array}{c}\text { Interval } \\
\text { since } \\
\text { Onset of } \\
\text { Interstitial } \\
\text { Keratitis } \\
\text { (yrs) }\end{array}$ & Presentation & $\begin{array}{l}\text { Visual } \\
\text { Acuity }\end{array}$ & $\begin{array}{l}\text { Cupping } \\
\text { of Discs }\end{array}$ & $\begin{array}{l}\text { Field } \\
\text { Defect }\end{array}$ & $\begin{array}{l}\text { Depth of } \\
\text { Anterior } \\
\text { Chambers }\end{array}$ \\
\hline \multirow{2}{*}{1} & \multirow{2}{*}{64} & \multirow{2}{*}{$\mathbf{F}$} & \multirow{2}{*}{54} & \multirow{2}{*}{$\begin{array}{l}\text { Deterioration of } \\
\text { vision } \mathbf{R}\end{array}$} & R $6 / 12$ & $\mathbf{R}+$ & $\mathbf{R}+$ & \multirow[t]{2}{*}{ Average } \\
\hline & & & & & L $1 / 60$ & L Not seen & L Not possible & \\
\hline \multirow{2}{*}{2} & \multirow{2}{*}{49} & \multirow{2}{*}{$\mathbf{F}$} & R 40 & & R 6/6 & $\mathbf{R}-$ & $\mathbf{R}-$ & \multirow[t]{2}{*}{ Average } \\
\hline & & & L 25 & Haloes L & L $6 / 9$ & $\mathbf{L}-$ & L- & \\
\hline \multirow{2}{*}{3} & \multirow{2}{*}{47} & \multirow{2}{*}{$\mathbf{F}$} & \multirow[t]{2}{*}{$\begin{array}{c}36 \\
\text { approx. }\end{array}$} & \multirow[t]{2}{*}{$\begin{array}{l}\text { Haloes and "'acute } \\
\text { glaucoma" } L\end{array}$} & R 6/24 & R Not seen & $\mathbf{R}$ - & \multirow[t]{2}{*}{ Shallow } \\
\hline & & & & & L $6 / 9$ & L - & L - & \\
\hline \multirow{2}{*}{4} & \multirow{2}{*}{53} & \multirow{2}{*}{$\mathbf{M}$} & \multirow[t]{2}{*}{37} & & R 6/36 & $\mathbf{R}$ - & $\mathbf{R}-$ & \multirow[t]{2}{*}{ Shallow } \\
\hline & & & & $\begin{array}{l}\text { Deterioration of } \\
\text { vision and haloes } \mathrm{L}\end{array}$ & L $6 / 5$ & L - & $\mathbf{L}-$ & \\
\hline \multirow{2}{*}{5} & \multirow{2}{*}{58} & \multirow{2}{*}{$\mathbf{M}$} & \multirow{2}{*}{37} & \multirow[t]{2}{*}{$\begin{array}{l}\text { Deterioration of } \\
\text { vision and haloes } \\
\qquad R\end{array}$} & R $6 / 6$ & R - & $\mathbf{R}-$ & \multirow[t]{2}{*}{ Shallow } \\
\hline & & & & & L $6 / 6$ & L - & L - & \\
\hline \multirow{2}{*}{6} & \multirow{2}{*}{58} & \multirow{2}{*}{$\mathbf{M}$} & \multirow{2}{*}{37} & $\begin{array}{l}\text { Deterioration of } \\
\text { vision and haloes } \\
\qquad R\end{array}$ & R $6 / 9$ & $\mathbf{R}+$ & $\mathbf{R}+$ & \multirow[t]{2}{*}{$\begin{array}{l}\text { Very } \\
\text { shallow }\end{array}$} \\
\hline & & & & & 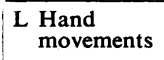 & L - & $\begin{array}{l}\text { L } \mathrm{Not}_{\text {possible }} \\
\text { posite }\end{array}$ & \\
\hline \multirow{2}{*}{7} & \multirow{2}{*}{39} & \multirow{2}{*}{$\mathbf{M}$} & R $15+$ & $\begin{array}{l}\text { Deterioration of } \\
\text { vision and haloes }\end{array}$ & R $6 / 9$ & $\mathbf{R}+$ & $\mathbf{R}+$ & Average \\
\hline & & & L 15 & & L $6 / 18$ & $L-$ & L - & \\
\hline 0 & 23 & $F$ & 16 & $\begin{array}{l}\text { Discovered in } \\
\text { survey of old } \\
\text { Interstitial Keratitis }\end{array}$ & R 6/18 & $\mathbf{R}++$ & $\mathbf{R}+$ & Average \\
\hline 0 & נol & 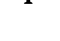 & 10 & & L 6/9 & $L-$ & L - & \\
\hline 9 & 36 & $\mathbf{F}$ & 24 & $\begin{array}{l}\text { Discovered in } \\
\text { survey of old } \\
\text { Interstitial Keratitis }\end{array}$ & R 6/60 & R Not seen & $\mathbf{R}$ - & Average \\
\hline & & & & & L $6 / 9$ & L ++ & $\mathbf{L}+$ & \\
\hline
\end{tabular}


cases reported above), the aetiological status of the interstitial keratitis must remain in doubt until more definite evidence is adduced to link the two conditions.

On the other hand, Cases 7, 8, and 9 have certain common features distinguishing them from the other six patients; they were all younger than 40 and already had advanced glaucoma. Each had extensive peripheral anterior synechiae in the

III

INACTIVE INTERSTITIAL KERATITIS AND GLAUCOMA

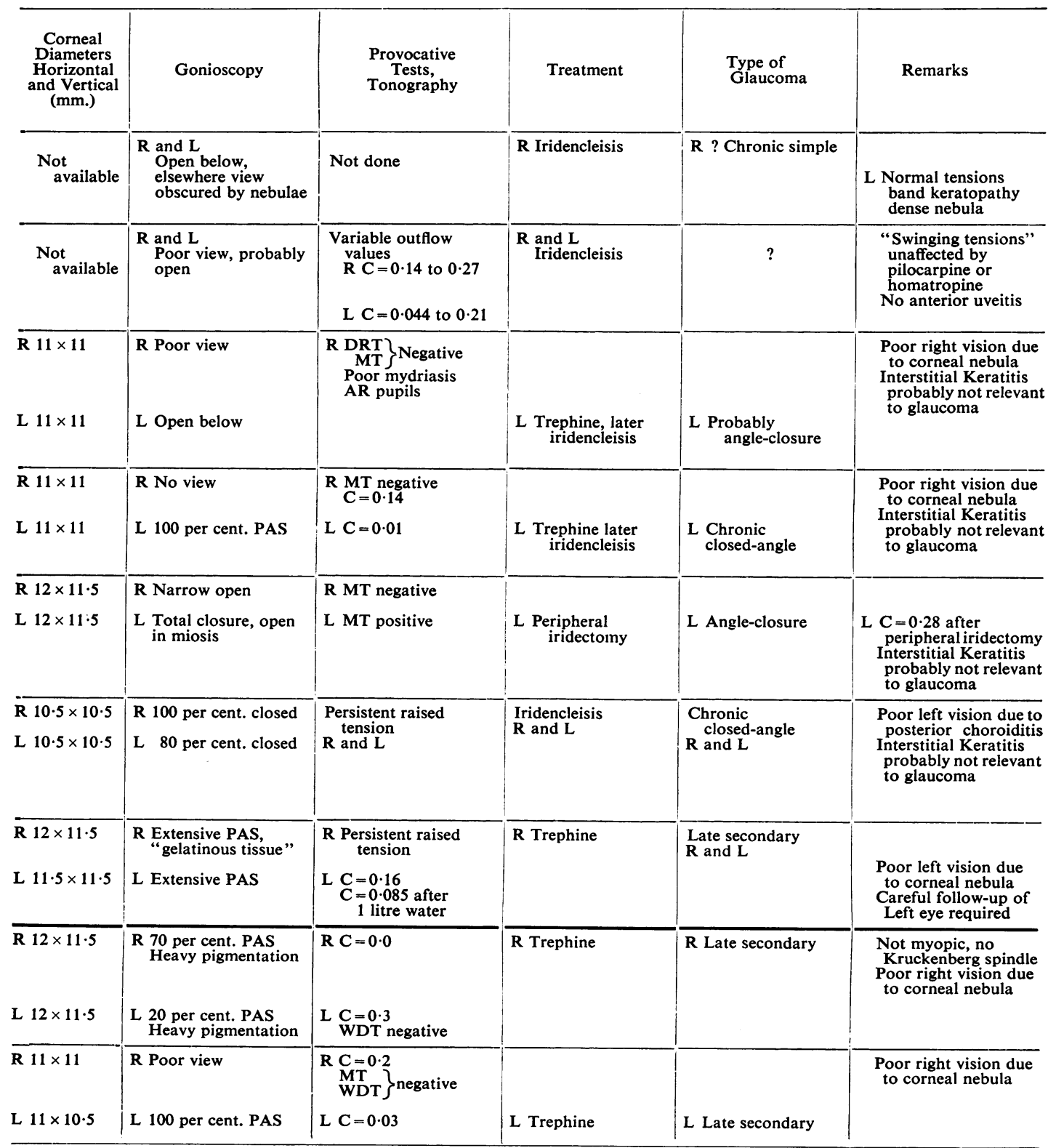


affected eyes. There were no findings to suggest either type of the primary glaucomas, and the impression in Case 8 was not that of pigmentary glaucoma. They were therefore considered to be examples of late secondary glaucoma.

From this small series of nine cases, therefore, these three alone emerge with a satisfactory clinical explanation for the development of late glaucoma due to interstitial keratitis, namely the presence of peripheral anterior synechiae caused by the anterior segment inflammation during the active phase of the interstitial keratitis; it is submitted that they form a clinical entity of true late secondary glaucoma. The open-angle type of glaucoma seen by Knox (1961) was not encountered in this series, and further studies with histological correlations are necessary to establish the cause of the obstruction to outflow in such cases.

\section{Summary}

95 patients (174 eyes) suffering from inactive syphilitic interstitial keratitis were examined, with particular reference to the state of the filtration angle.

Two patients with advanced glaucoma were found.

The gonioscopic, tonometric, and tonographic findings are discussed.

The clinical features of the two patients with glaucoma revealed in this survey, together with those of seven other patients with known glaucoma and inactive interstitial keratitis, are discussed.

We are grateful to Mr. O. M. Duthie and Mr. R. Dalgleish for permission to report cases under their care. We acknowledge the helpful advice of Dr. E. J. Naylor on many points.

Our special thanks are due to Dr. S. M. Laird, Director of the Department of Venereal Diseases, Manchester Royal Infirmary, for his constant encouragement and for providing the data from the records of his Department.

\section{REFERENCES}

Ashworth, A. N. (1958). Brit. J. vener. Dis., 34, 83.

Cunningham, J. F. (1922). Trans. ophthal. Soc. U.K., $42,44$.

DUKE-ElDER, S. (1938a). "Text-book of Ophthalmology", vol. 2, p. 1976. Kimpton, London. (1938b). Ibid., p. 1973

(1961). "System of Ophthalmology", vol. 2, p. 93. Kimpton, London.

Fuchs, E. (1899). "Text-book of Ophthalmology", 2nd Amer. ed., authorized trans. rev. from 7th German ed. by A. Duane, p. 192 . Lewis, London.

Gorin, G., and Posner, A. (1957). "Slit-lamp Gonioscopy". Williams and Wilkins, Baltimore.

Higgit, A. C. (1956). Trans. ophthal. Soc. U.K., 76, 73.

Hutchinson, J. (1863). "Diseases of the Eye and Ear consequent upon Inherited Syphilis", p. 170. Churchill, London.

Knox, D. L. (1961). A.M.A. Arch. Ophthal., 66, 18.

KraUPA, E. (1934). Z. Augenheilk., 84, 43.

Oksala, A. (1957). Amer. J. Ophthal., 43, 719.

Schulmann, F. (1934). Klin. Mbl. Augenheilk., 92, 522.

SCHWEINITZ, G. E. DE (1916). "Diseases of the Eye", 8th ed., p. 269. Saunders, Philadelphia; London.

SPICER, W. T. H. (1924). Brit. J. Ophthal., Monograph Suppl. 1.

Sugar, H. S. (1962). Amer. J. Ophthal., 53, 602.

Tulloh, C. G. (1960). Trans. ophthal. Soc. U.K., 80, 187. 